\title{
PRIMENA SOFTVERSKIH TEHNOLOGIJA U PRAĆENJU I ANALIZI STANJA ŽIVOTNE SREDINE NA OSNOVU OTVORENIH PODATAKA
}

\section{APPLICATION OF SOFTWARE TECHNOLOGIES IN MONITORING AND ANALYSIS OF THE STATE OF THE ENVIRONMENT ON THE BASIS OF OPEN DATA}

\author{
Ivana Rabuzin, Fakultet tehničkih nauka, Novi Sad
}

\begin{abstract}
Oblast - INFORMACIONI INŽENJERING
Kratak sadržaj - U ovome radu istražene su mogućnosti primene otvorenih podataka $i$ softverskih tehnologija $u$ praćenju i analizi stanja životne sredine. Implementiran je prototip softverskog rešenja koje vizualizuje skupove otvorenih podataka Republike Srbije o zagadivačima vazduha, vode $i$ zemljišta, kao i zagađivačima otpadom. Prototip podržava praćenje neverifikovanih satnih podataka o kvalitetu vazduha u realnom vremenu.
\end{abstract}

Ključne reči: Otvoreni podaci, Jezik $R$, Vizualizacija, Zagađenje životne sredine, Zaštita životne sredine

\begin{abstract}
The paper investigates the possibilities of the application of open data and software technologies in monitoring and analysis of the state of the environment. A prototype of a software solution has been implemented. It visualizes sets of open data of the Republic of Serbia on air, water, and soil pollutants, as well as waste pollutants. The prototype supports real-time monitoring of unverified hourly data on air quality.
\end{abstract}

Keywords: Open data, $R$ language, Visualization, Environmental pollution, Environmental protection

\section{UVOD}

Zdrava životna sredina je od izuzetnog značaja za očuvanje razvoja čitavog društva. Odgovornost i informisanost nas samih dovodi do očuvanja i unapređenja životne sredine, a ujedno života ljudi i opstanka biljnog i životinjskog sveta. Koncept otvorenih podataka daje mogućnost obrade podataka iz različitih domena bez posebnih ograničenja od strane autora.

Podaci mogu biti iz prošlosti ili oni koji opisuju stanje $u$ realnom vremenu, pa se u zavisnosti od vremenskog perioda mogu generisati dodatni izveštaji i analize ili pratiti trenutno stanje.

Ovaj rad se bavi istraživanjem mogućnosti primene otvorenih podataka i softverskih tehnologija u monitoringu i analizi stanja životne sredine. Pomoću odgovarajućih skupova otvorenih podataka moglo bi se na nivou grada ili regiona pratiti koji deo je najviše zagađen i kojom zagađujućom materijom. U slučaju da je trend zagađenja konstantan onda bi se $\mathrm{u}$ kratkom vremenskom periodu mogle preduzeti odgovarajuće mere zaštite.

\section{NAPOMENA:}

Ovaj rad proistekao je iz master rada čiji mentor je bio dr Vladimir Ivančević, docent.
Analizirane su dostupnost i odlike otvorenih podataka o stanju životne sredine, kao i pogodne softverske tehnologije za korišćenje u prikazu, obradi i analizi otvorenih podataka. $\mathrm{Za}$ potrebe ilustracije primene softverskih tehnologija odabrani su otvoreni skupovi podataka o zagađivačima vazduha, vode, zemljišta i zagađivačima otpadom u Republici Srbiji. Implementiran je prototip softverskog rešenja za praćenje i analizu stanja životne sredine na osnovu otvorenih podataka i data je ocena implementiranog prototipa.

\section{2. ŽIVOTNA SREDINA}

Po Zakonu o zaštiti životne sredine [1], životna sredina jeste skup prirodnih i stvorenih vrednosti čiji kompleksni međusobni odnosi čine okruženje, odnosno prostor i uslove života. Zagađivanje životne sredine je nešto sa čime se susrećemo u svakodnevnom životu i tema kojom se bave razna istraživanja. Unošenjem štetnih materija $u$ životnu sredinu dolazi do zagađenja, kako ljudskom delatnošću tako i nekim prirodnim procesima koji mogu imati štetne posledice po zdravlje ljudi [2]. Zagađujuće materije (polutanti) predstavljaju supstance čije postojanje u životnoj sredini utiče ili može uticati štetno na prirodni sastav, osobine i integritet životne sredine [3].

Zbog svega navedenog, zaštita životne sredine je veoma bitna, jer jedino tako možemo očuvati biološku ravnotežu. Svaki poremećaj stanja životne sredine dovodi do ekoloških poremećaja, ali i do poremećaja socijalnih odnosa, koji su međusobno povezani [2]. U radu će biti razmatrani podaci o zagađivanju vazduha, vode, zemljišta, kao i zagađivanju otpadom.

\subsection{Zagađivanje vazduha}

Izvori zagađenja vazduha mogu biti prirodni (vulkani, pustinjski pesak, gejziri, gasovi iz močvara, šumski požari) i antropogeni (industrija, saobraćaj, termoelektrane, toplane, poljoprivreda) [3]. Vazduh najčešće zagađuju štetne materije kao što su sitne čestice prašine i čađi, sumpor-dioksid, ugljenmonoksid, izduvni gasovi iz automobila [4].

Za indikator kvaliteta vazduha koristi se broj dana u toku jedne godine $\mathrm{s}$ dnevnim koncentracijama zagađujućih materija $\mathrm{SO}_{2}, \mathrm{NO}_{2}, \mathrm{PM}_{10}$ i $\mathrm{O}_{3}$ većim od propisane granične vrednosti [5]. Počevši od 2011. godine u Novom Sadu je izražen opadajući trend prekoračenja dnevnih vrednosti svih parametara kvaliteta vazduha, a ozon se samo sporadično pojavljuje kao uzročnik lošeg kvaliteta vazduha [5]. 


\subsection{Zagađivanje vode}

Pored količine vode koja je čoveku dostupna, veoma je važan i njen kvalitet. Pokazatelji kvaliteta vode mogu biti [6]:

1. fizički - suspendovane materije, mutnoća, boja, ukus, miris, temperatura;

2. hemijski - ukupne rastvorene materije, $\mathrm{pH}$, alkalitet, tvrdoća, rastvoreni gasovi, metali, organska materija, hranljiva materija;

3. biološki - stepen saprobnosti, stepen biološke proizvodnje, mikrobiološki pokazatelji, stepen otrovnosti, indeks razlike.

Putem industrije, poljoprivrede i stanovništva zagađuju se vodene površine, ali i unošenjem u njih različitih produkata raspadanja ostatka flore $\mathrm{i}$ faune $\mathrm{i}$ erozijom zemljišta pod dejstvom površinskog oticanja [2].

\subsection{Zagađivanje zemljišta}

Zagađenje zemljišta podrazumeva unošenje zagađujućih materija u ili na zemljište delovanjem čoveka ili prirodnim procesima, što može imati štetne posledice na kvalitet životne sredine i zdravlje ljudi [7]. Prisustvo zagađujućih materija iznad propisanog nivoa najčešće potiče od unošenja pesticida, izluživanja zagađujućih materija iz otpada sa deponija, direktnim odlaganjem otpada na zemljište ili curenja opasnih i štetnih materija iz nadzemnih rezervoara [8]. Čovek nepravilnim odlaganjem otpada stvara i tzv. divlje deponije, koje predstavljaju izvor zaraza i jedan od velikih zagađivača tla.

U 2018. godini je praćen stepen ugroženosti zemljišta Republike Srbije od hemijskih zagađenja u urbanim zonama u 18 jedinica lokalne samouprave i najčešće prekoračenje graničnih vrednosti zabeleženo je za materije $\mathrm{Zn}, \mathrm{Cu}, \mathrm{Ni}, \mathrm{Co}, \mathrm{Cd}, \mathrm{PCB}$ i DDE/DDD/DDT [9].

\subsection{Zagađivanje otpadom}

Otpad predstavlja proizvod koji više ne zadovoljava nijednu ljudsku potrebu, a čine ga materijali, energija nusproizvodi koji se odbacuju u životnu sredinu kao krajnje odlagalište, jer nemaju nove vrednosti [3]. Ogromne količine pepela, stakla, hartije, razne vrste ambalaže od plastike i drugih materijala, otpaci iz industrije $\mathrm{i}$ termoelektrana, predstavljaju značajne izvore zagađivanja životne sredine [4]

Količina čvrstog otpada se povećava iz godine u godinu, a sve manje je raspoloživog prostora za deponije [2]. Otpad možemo podeliti na [3]:

- onaj koji možemo ponovo iskoristiti u proizvodnji iz koje je nastao ili u drugim proizvodnim procesima, kao sekundarnu sirovinu,

- onaj koji se u neizmenjenom obliku odlaže na deponije $\mathrm{i}$

- onaj otpad koji se mora prerađivati posebnim postupcima da ne bi bio opasan po okolinu prilikom deponovanja.

Na sajtu Agencije za zaštitu životne sredine Republike Srbije (sepa.gov.rs) možemo da vidimo izveštaje o upravljanju ambalažom i ambalažnim otpadom, plastičnim kesama i proizvodima koji nakon upotrebe postaju posebni tokovi otpada. Prema mestu nastanka otpad možemo podeliti na otpad iz domaćinstva, industrije, poljoprivrede, otpad koji nastaje pri vađenju sirovina iz zemlje i proizvodnji energije [3].

\section{OTVORENI PODACI O ŽIVOTNOJ SREDINI}

U ovome radu koristićemo skupove otvorenih podataka, koji su svima dostupni za korišćenje i mašinski su obradivi, pa mogu odmah biti u upotrebi kroz različite aplikacije.

Prema jednoj od definicija otvoreni podaci (engl. open data) su ,koncept javno dostupnih podataka na način da svako lice može slobodno da ih koristi i ponovo objavljuje, bez ograničenja od strane autora ili drugih kontrolnih mehanizama" [10]. Glavne karakteristike otvorenih podataka su [11]:

- dostupnost - podaci su otvoreni u celosti i mogu se preuzimati sa Interneta;

- ponovna upotreba i distribucija - podaci su čitljivi i dostupni u formatima koji dozvoljavaju ponovnu upotrebu, po potrebi i spajanje sa drugim skupovima otvorenih podataka;

- univerzalno učešće - upotreba podataka, ponovna upotreba i distribucija su omogućeni svima, bez obzira na područje rada.

$\mathrm{Na}$ portalu otvorenih podataka Republike Srbije (data.gov.rs) postoje skupovi otvorenih podataka iz različitih domena, kao i njihovi primeri upotrebe. U Republici Srbiji zvanične institucije kao što su ministarstva, agencije i Republički zavod za statistiku su otvorile neke od svojih podatka.

$\mathrm{Na}$ osnovu analize skupova podataka iz domena zaštite životne sredine koji su dostupni na portalu otvorenih podataka Republike Srbije, za upotrebu su prvo odabrani skupovi podataka o zagađivačima vazduha, vode, zemljišta i zagađivačima otpadom:

- podaci o zagađivačima vazduha za period od 2010. do 2017. godine nalaze se u datoteci airemissionsperyearview-2010-2017.csv,

- $\quad$ podaci o zagađivačima vode za vremenski period od 2011. do 2017. godine nalaze se u datoteci wateremissionsperyearview-2011-2017.csv,

- podaci o zagađivačima zemljišta za vremenski period od 2005. do 2016. godine nalaze se u datoteci ispitivanjezemljista2005-2016.csv,

- $\quad$ podaci o zagađivačima otpadom za vremenski period od 2010. do 2017. godine nalaze se u datoteci wastegeneratedperyearview-export2010-2017.csv

Sa istog portala odabrani su i neverifikovani satni podaci o kvalitetu vazduha u realnom vremenu:

- $\quad$ podaci o merenim materijama kvaliteta vazduha nalaze se u datoteci component.csv,

- podaci o stanicama za merenje kvaliteta vazduha nalaze se u datoteci station.csv,

- podaci o satnim merenjima kvaliteta vazduha nalaze se u datoteci air_data.csv.

\section{PROTOTIP SOFTVERSKOG REŠENJA}

Skupovi otvorenih podataka daju mogućnost kako praćenja stanja životne sredine u realnom vremenu, tako i analize podataka u određenim vremenskim periodima iz prošlosti. Što su podaci obimniji, analize podatka mogu biti detaljnije i preciznije. Očuvanje životne sredine i smanjenje uticaja pojedinih zagađivača na nju su aktuelne 
teme svakodnevnice. Jedan od motiva za izradu ove aplikacije je upravo praćenje određenih zagađivača.

\subsection{Implementacija prototipa}

Za implementaciju prototipa softverskog rešenja korišćen je programski jezik $R$ (r-project.org) i paket shiny (shiny.rstudio.com). $R$ je programski jezik za statističku analizu, grafičko predstavljanje podataka i izveštavanje, a paket shiny omogućava pravljenje veb aplikacija koje poseduju interaktivni grafički korisnički interfejs.

Grafički korisnički interfejs razvijenog prototipa organizovan je kroz četiri celine:

- monitoring kvaliteta vazduha neverifikovanih satnih podataka,

- tabelarni prikaz podataka,

- vizualizacija podataka,

- liste korišćenih otvorenih skupova podataka.

Na slici 1. prikazan je izgled početnog ekrana razvijenog prototipa softverskog rešenja. Početni ekran je posvećen monitoringu neverifikovanih satnih podataka o kvalitetu vazduha u realnom vremenu. Korisnik može da vrši filtriranje podataka po kolonama u tabeli, sortiranje, pretraživanje sadržaja tabele, selekciju kolona za prikaz i izbor broja redova za prikaz.

Za vremenski interval i odabranu zagađujuću materiju koji su selektovani u odgovarajućim poljima, generisani stubičasti grafikon (engl. bar plot) prikazuje pet stanica sa najvećom koncentracijom zagađujuće materije u odabranom vremenskom periodu.

Kroz deo za monitoring korisnik može da prati neverifikovane satne podatke zagađujućih materija u realnom vremenu sa određenog mesta očitavanja i uporedi trenutno stanje, na primer sa merenjima iz skupa podataka za zagađivače vazduha ponuđenih u delu aplikacije za vizualizaciju (ako merenja koncentracija za odgovarajuću zagađujuću materiju i odabrani region postoje).

U okviru ekrana za tabelarni prikaz podataka, moguće je selektovati neki od ponuđenih skupova podataka o zagađivačima vazduha, vode, zemljišta i zagađivačima otpadom, a po zadatim kriterijumima izvršiti filtriranje i posmatrati koncentracije odabranih zagađujućih materija po željenom vremenskom periodu. Podaci obuhvaćeni tabelarnim prikazom mogu biti sačuvani $u$ formatima CSV, TSV i DOC.

Unutar ekrana za vizualizaciju podataka korisnik za odabrani skup podataka selektovanjem odgovarajućih varijabli, kao i varijable za prikaz, može da vrši filtriranje i dobije odgovarajuću vizualizaciju pomoću kutijastog grafikona (engl. box plot) i histograma. Generisane grafikone moguće je preuzeti u formatima PNG ili PDF. Sumarni tekstualni prikaz podataka po svakom od tri moguća filtera odabranih varijabli prikazan je unutar odgovarajuće sekcije.

U nastavku je dat jedan od primera filtriranja skupova podataka po selektovanim varijablama. Ako odaberemo skup podataka za vazduh i izvršimo filtriranje po Beogradskoj oblasti postrojenja za mesta Rakovica, Padinska Skela i Čukarica, primećujemo da imamo atipičnu vrednost (engl. outlier) za koncentracije suspendovane čestice $\mathrm{PM}_{10}$ iz 2017. godine (Slika 2.).

Iz same medijane možemo da zaključimo da raspodela koncentracije zagađujuće materije nije simetrična. Povećana koncentracija suspendovane čestice može biti detektovana preko ekrana za tabelarni prikaz primenom odgovarajućih filtera, a možemo i da utvrdimo koje tačno postrojenje emituje povećanu koncentraciju zagađujuće materije.

\subsection{Ocena prototipa}

$\mathrm{Na}$ zvaničnom portalu državne mreže za automatski monitoring kvaliteta vazduha (amskv.sepa.gov.rs) može da se dobije objedinjeni prikaz preliminarnih, neverifikovanih podataka o kvalitetu vazduha $\mathrm{u}$ realnom vremenu za Republiku Srbiju.

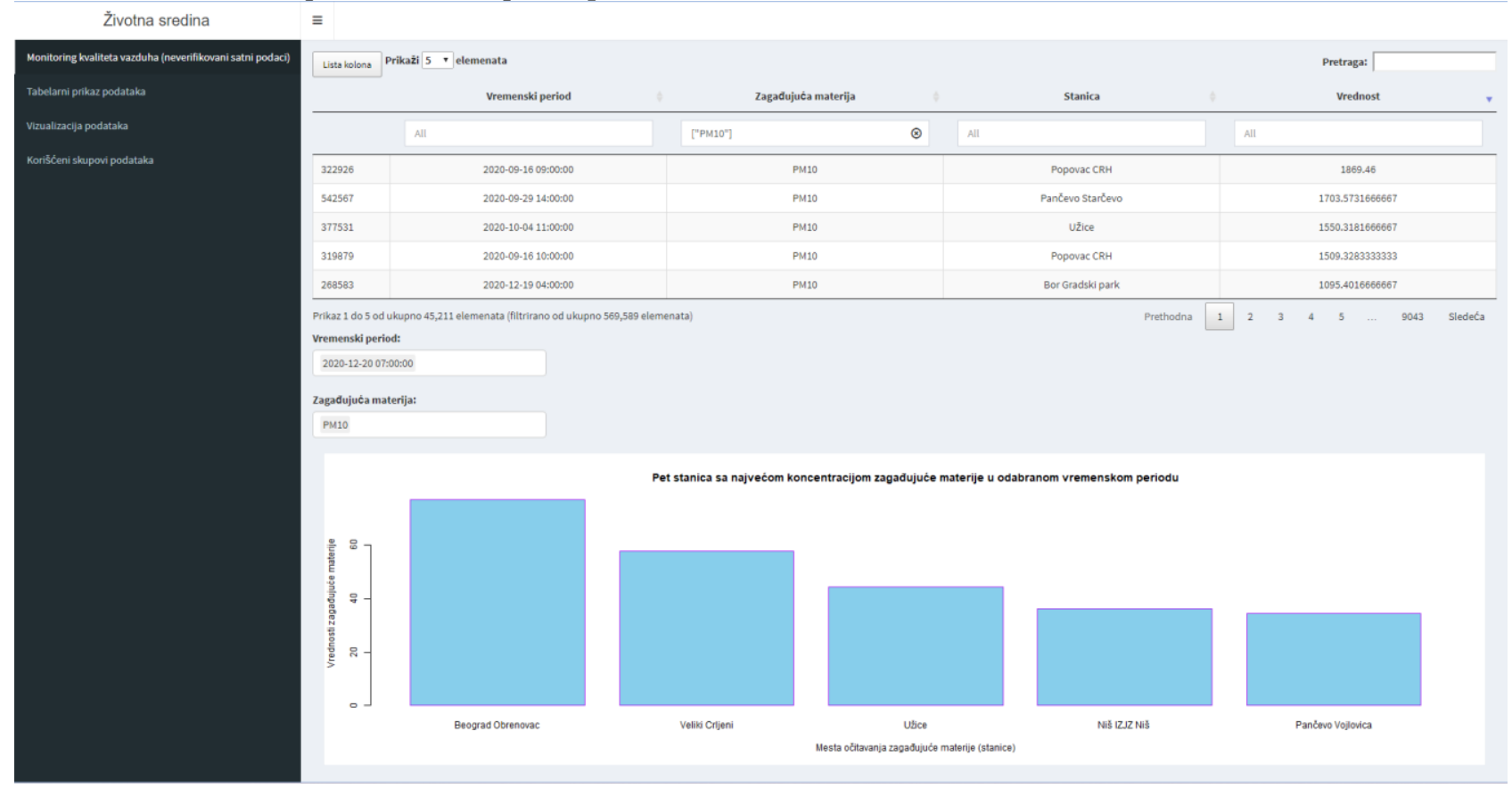

Slika 1. Ekran za prikaz kvaliteta vazduha (neverifikovani satni podaci) u razvijenom prototipu softverskog rešenja 


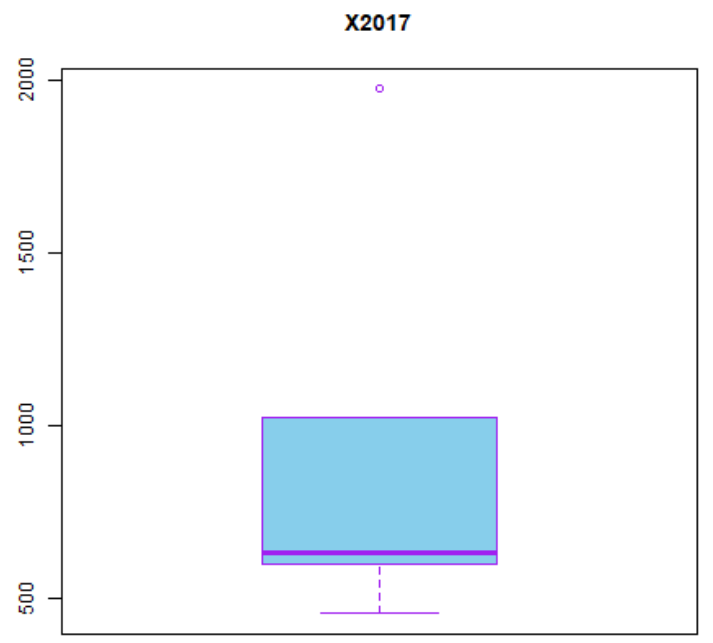

Slika 2. Kutijasti grafikon za koncentraciju suspendovanih čestica $P M_{10}$ u odabranim mestima Rakovica, Padinska Skela i Čukarica za 2017. godinu

Pregled podataka na portalu je dat na dnevnom, nedeljnom i mesečnom nivou. Prototip softverskog rešenja u ovome radu koristi iste podatke za monitoring kao i portal amskv. Prednost razvijenog prototipa u odnosu na portal amskv je mogućnost da korisnik bira vremenski period merenja zagađujuće materije kako bi mu se generisao vizualni prikaz pet stanica koje imaju najveću koncentraciju odabrane materije.

Preko portala za stanje kvaliteta voda u Republici Srbiji (77.46.150.213:8080/apex/f? $p=406: 4: \ldots:::)$ moguće je dobiti pregled stanja kvaliteta vode vodotoka za odabrani dan, dijagramski prikaz izmerene vrednosti izabranog parametra po stanicama za zadate vremenske filtere, preuzeti podatke u formatu CSV i drugo. Prototip softverskog rešenja se ne bavi kvalitetom voda, već zagađenjem vode i nudi tabelarni prikaz odgovarajućih podataka, mogućnost filtriranja po više selektovanih varijabli i vizualizacije odabranih podataka.

\subsection{Budući razvoj prototipa}

Prikazi podataka u razvijenom prototipu mogu biti prošireni po uzoru na prikaz zagađivača vazduha sa sajta aqicn.org, na primer da se vizualizacija sprovodi na mapi. Prototip softverskog rešenja bi dalje mogao biti unapređen uvođenjem formi za dodatnu obradu istorijskih podataka i generisanje izveštaja. U zadatom vremenskom intervalu mogla bi biti praćena koncentracija zagađujućih materija učitanog skupa podataka na nivou mesta, a odabrani podaci bi mogli biti izvezeni ili korišćeni dalje pri vizualizaciji.

\section{ZAKLJUČAK}

Implementirani prototip softverskog rešenja podržava pregled i vizualizaciju učitanih podataka o zagađivačima vazduha, vode, zemljišta, kao i zagađivačima otpadom. Podržan je pregled kvaliteta vazduha u realnom vremenu zasnovan na neverifikovanim satnim podacima.
Rešenje može koristiti osobama na koje zbog određenih zdravstvenih problema zagađenje vazduha utiče posebno nepovoljno. Takve osobe mogu pratiti koncentracije zagađivača u realnom vremenu i zahvaljujući tome smanjiti izloženost štetnim materijama.

Donosioci odluka iz nadležnih državnih institucija mogu na osnovu analiza istorijskih podataka planirati strategije i kampanje sa ciljem zaštite životne sredine. Naučnici bi mogli koristiti podatke o prisustvu zagađivača u životnoj sredini i na osnovu njih izvoditi hipoteze o štetnim uticajima zagađujućih materija na zdravlje ljudi.

Razmatrani skupovi otvorenih podataka o zagađenju imaju izvesna ograničenja. U pojedinim skupovima podataka nisu dostupna očitavanja sa svih mernih stanica i za sve zagađivače, stoga nije ni moguće uvek napraviti sveobuhvatne analize.

Poželjno je da podaci budu što obimniji i raznovrsniji, a njihovo ažuriranje, ako je to moguće, u realnom vremenu i što češće. Bez obzira na prethodna ograničenja, upotreba trenutno dostupnih skupova otvorenih podataka može doprineti zaštiti životne sredine.

\section{LITERATURA}

[1] Zakon o zaštiti životne sredine ("Službeni glasnik Republike Srbije", broj 95/2018)

[2] O. Novitović, D. Ranđić, A. Novitović, "Zaštita životne sredine", 2009.

[3] Lj. Blagojević, "Životna sredina i zdravlje”, Univerzitet u Nišu, 2012.

[4] Enciklopedija "Izvori i uzroci zagađenja životne sredine" tehnologijahrane.com

[5] Ministarstvo zaštite životne sredine, "Vazduh i klimatske promene" indicator.sepa.gov.rs

[6] http://polj.uns.ac.rs/wpcontent/uploads/2014/04/Opsta-UV-Hemija-vode.pdf (pristupljeno u oktobru 2020.)

[7] Zakon o zaštiti zemljišta ("Službeni glasnik Republike Srbije", broj 112/2015) pravno-informacioni-sistem.rs

[8] N. Stojić, S. Štrbac, D. Prokić, "Soil Pollution and Remediation" Handbook of Environmental Materials Management, Springer, Cham, 2018, 1-34.

[9] http://www.sepa.gov.rs/download/Izvestaj2018.pdf (pristupljeno u novembru 2020.)

[10] arhiva.ite.gov.rs/latinica/otvoreni-podaci-160801.php (pristupljeno u septembru 2020.)

[11] http://arhiva.ite.gov.rs/latinica/otvoreni-podaci160808.php (pristupljeno u septembru 2020.)

\section{Kratka biografija:}

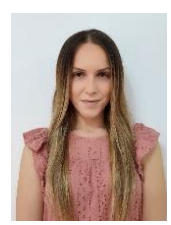

Ivana Rabuzin rođena je 04.12.1989. godine u Bihaću, BiH. U oktobru 2014. godine odbranila je master rad na Prirodno-matematičkom fakultetu pod nazivom „Lukasov model ekonomskog rasta i varijaciona formulacija". Master studije na Fakultetu tehničkih nauka na studijskom programu Informacioni inženjering upisala je oktobra 2017. 